Jackson, F. L. \& Copping, Alice M. (1952). J. gen. Microbiol. 7, 107-116

\title{
Some Aspects of the Growth of Proteus vulgaris with Limiting Concentrations of Nicotinic Acid
}

\author{
By F. L. JACKSON aNd ALICE M. COPPING* \\ National Institute for Medical Research, Mill Hill, London, N.W. 7, and \\ Lister Institute of Preventive Medicine, London, S.W. 1
}

SUMMARY: When Proteus vulgaris is grown in a simple defined medium with limiting concentrations of nicotinic acid but all other constituents in excess, growth as measured by dry-weight determinations continues for several hours after the disappearance of all detectable nicotinic acid from the medium. A linear phase of protoplasmic synthesis and of oxygen uptake follows this disappearance and lasts for 2.5-3 hr., while the amount of recoverable nicotinic acid in the cells remains constant. It is suggested that, during the period of linear growth, the rate of protoplasmic synthesis is determined by the presence within the total cell population of a more or less constant amount of nicotinic acid or its active derivatives.

When an organism grows under specified conditions, protoplasmic synthesis follows a characteristic course, and the more precisely the conditions of both inoculum and medium can be controlled, the more reproducible will be the results of growth experiments. For quantitative growth studies and for some investigations of metabolism, it may be of particular value if growth is limited by the concentration of a known single factor. Some microbiological assays depend on measurement of the growth response of an organism under conditions in which the concentration of the substance being assayed is the sole limiting factor. The relation between utilization of the factor and the course of protoplasmic synthesis is therefore of interest, and may be expected to vary in different cases. If the factor is inactivated quickly after assimilation, growth may soon cease when an external supply is no longer available. Where inactivation of the factor is less rapid, a stage will be reached when no external supply remains, but the cells contain a certain amount of the factor, or of its derivatives, in a functional state. In such a case, particularly if the factor is to function as a coenzyme for a limited number of enzyme reactions, cell substances whose synthesis is not directly dependent on the utilization of the factor as a 'building block' might still be formed. In other words, in certain cases, although no external supply of the growth factor remains, cell growth might be expected to continue for a considerable period.

Nicotinic acid is a growth factor for certain organisms and is known to be required for the formation of the pyridine nucleotide coenzymes. A culture of an organism unable to synthesize nicotinic acid might continue to grow after all the growth factor had been assimilated if active nicotinic acid derivatives were available in the cells. If, for a certain period, the activity of these derivatives was more or less constant, the rate of protoplasmic synthesis

* Present addres: Physiology Department, King's College of Household and Social Science, London, W. 8. 
might become constant, being determined by the activity of those enzyme systems dependent on the supply of nicotinic acid. Under these circumstances, a linear growth phase would occur, and would continue until there was significant inactivation of the nicotinic acid derivatives, or until some other change in conditions limited growth.

To test the possibilities outlined, we have investigated the growth of a strain of Proteus vulgaris in a simple defined medium under conditions in which nicotinic acid concentration was the sole factor limiting growth.

\section{METHODS}

Organism. A strain of P. vulgaris, C.N. 2433, obtained from $\mathrm{Mr}$ H. Proom of the Wellcome Research Laboratories, Beckenham, was selected from a number of strains tested and was used throughout. It was maintained on meat-digest agar slopes. Before use, subcultures were made in defined medium containing a limiting quantity of $0.03 \mu \mathrm{g}$. nicotinic acid $/ \mathrm{ml}$. Inocula from such cultures were twice washed with nicotinic acid-free medium before use. Glass-distilled water was used for all solutions and washings unless otherwise stated.

Medium. Preliminary experiments were made with an ammonium lactate medium based on that of Fildes (1938). The effects of varying the concentrations of lactate and ammonium salts, with different concentrations of nicotinic acid, were investigated and a medium was devised which allowed nicotinic acid concentration to be made the sole limiting factor for growth, all other constituents being present in excess. The final composition of the medium adopted was: $\mathrm{M}-\mathrm{KH}_{2} \mathrm{PO}_{4}, 15 \mathrm{ml}$; $\mathrm{M}-\mathrm{NH}_{4} \mathrm{Cl}, 18 \mathrm{ml}$.; $0 \cdot 2 \mathrm{M}-\left(\mathrm{NH}_{4}\right)_{2} \mathrm{SO}_{4}, 36 \mathrm{ml}$; $0.5 \mathrm{M}$-lactate, $90 \mathrm{ml}$. ; 0.0167 M- $\mathrm{MgSO}_{4}, 4.5 \mathrm{ml}$. ;0.002 $\mathrm{M}-\left(\mathrm{NH}_{4}\right)_{2} \mathrm{SO}_{4} . \mathrm{FeSO}_{4} \cdot 6 \mathrm{H}_{2} \mathrm{O}$, $11.25 \mathrm{ml}$; nicotinic acid solution (concentration varied), $4.5 \mathrm{ml}$; d distilled water to $450 \mathrm{ml}$; $\mathrm{pH}$ adjusted to $\mathbf{7 \cdot 2}$.

The lactate solution was prepared from analytical quality lactic acid; $4.5 \mathrm{~g}$. of the acid were diluted with $20 \mathrm{ml}$. water, and the $\mathrm{pH}$ of the boiling solution adjusted to 7.0 with $\mathrm{x}-\mathrm{NaOH}$. The volume was made up to $100 \mathrm{ml}$.

The ferrous ammonium sulphate solution was made up in $0.02 \mathrm{~N}-\mathrm{HCl}$ and sterilized by Seitz filtration. The lactate solution was autoclaved at a pressure of $10 \mathrm{lb}$. for $10 \mathrm{~min}$. and the mixture of inorganic salts was autoclaved as a separate solution.

Stock nicotinic acid solution $(0.001 \mathrm{M})$ was sterilized by Seitz filtration.

Cultures were grown in Erlenmeyer flasks at $36^{\circ}$ and were shaken continuously during growth at a rate of 92 complete oscillations/min. and an amplitude of 5 in. This ensured adequate aeration, and increased rate of shaking did not increase the growth rate or the final yield. Quantities of culture medium varied from $10 \mathrm{ml}$. in a $50 \mathrm{ml}$. flask to $300 \mathrm{ml}$. in a $3 \mathrm{l}$. flask.

Opacity measurements. Opacities were measured by means of a Spekker absorptiometer using filters $\mathrm{H} 508$, with defined medium in the blank cell. The dry weight-opacity relationship was determined for organisms harvested at the end of the exponential phase of growth in defined medium and for organisms 
harvested after cessation of growth, and was found to be the same in each case The dry weight (at $110^{\circ}$ ) was determined on suitable samples of the thricewashed original heavy suspension.

Total counts. A Helber counting chamber was used, with low-power darkground illumination and a $\times 25$ compensating eye-piece, following the method described by Wilson (1922). Samples $(1 \mathrm{ml}$.) of culture were transferred to $1 \mathrm{ml}$. phenol saline, and any further dilution necessary was made with water.

Viable counts. The method of Miles \& Misra (1938) was used. Plates were prepared with meat infusion agar (Wright, 1933), containing sodium lactate (10 mg./ml.), and boric acid (1 $\mathrm{mg} . / \mathrm{ml}$.) was added to inhibit swarming (Sykes \& Reed, 1949).

Nitrogen determinations. Cells from $10 \mathrm{ml}$. samples of culture were washed three times with water at $4^{\circ}$. Their nitrogen content was determined by a modification of the Kjeldahl method described by Miller \& Houghton (1945), a Markham distillation apparatus being used.

Oxygen uptake. Samples $(2 \cdot 6 \mathrm{ml}$.) of culture which had reached measurable opacity were transferred to Warburg manometer vessels with $\mathbf{0} \cdot \mathbf{2} \mathrm{ml}$. KOH and a filter-paper strip in the centre well and air in the gas phase. They were shaken at 120 oscillations $/ \mathrm{min}$. in a bath at $36^{\circ}$. Growth curves for these experiments were prepared from culture samples shaken in $50 \mathrm{ml}$. flasks in the same bath.

Nicotinic acid assays. The method of Barton-Wright (1946) was used. For each estimation, cells from $200 \mathrm{ml}$. samples of culture were collected by centrifugation at 12,500 r.p.m. in an angle centrifuge and washed twice at $4^{\circ}$ with nicotinic acid free medium before acid extraction. Omission of the washing of cells harvested from cultures with no detectable nicotinic acid in the supernatant fluid did not affect the result.

\section{RESULTS}

\section{Growth in the medium}

The term 'growth' is here used to denote increase of the total mass of bacterial protoplasm in the culture, as estimated by dry-weight determinations based on opacity readings. Curves of total numbers and of cell nitrogen will be referred to as such, and will not be called growth curves.

In a series of cultures in which nicotinic acid concentration ranged from 0 to $0.05 \mu \mathrm{g} . / \mathrm{ml}$, the curve relating dry wt. $/ \mathrm{ml}$. after $48 \mathrm{hr}$. incubation to initial nicotinic acid concentration was linear; concentrations of nicotinic acid above $0.05 \mu \mathrm{g} . / \mathrm{ml}$. gave progressively less increase, until a maximum dry weight was reached at about $0 \cdot 10 \mu \mathrm{g} . / \mathrm{ml}$. Results after $72 \mathrm{hr}$. incubation were the same as at $48 \mathrm{hr}$. and variations from batch to batch of medium were slight. In the experiments to be described, nicotinic acid concentrations corresponding to values on the linear part of the standard curve were used, and varied in different experiments from 0.02 to $0.03 \mu \mathrm{g} . / \mathrm{ml}$. With a concentration of $0.03 \mu \mathrm{g} . / \mathrm{ml}$. the $\mathrm{pH}$ of the medium at the end of growth had risen to $7 \cdot 6$. 
The inoculum was about $2 \times 10^{4}$ viable cells $/ \mathrm{ml}$. medium and a measurable opacity developed after 18-22 hr. Total counts were possible before there was sufficient growth to allow accurate dry-weight estimations. The time at which observations were begun is shown as zero time in the figures, since in this investigation the later phases of growth are of particular interest, and slight variations in the time interval between inoculation and development of a measurable opacity were not associated with significant changes in the later growth phases. Increasing the inoculum tenfold shortened the lag-phase but did not affect the final cell mass or the form of the later phases of the growth curve.

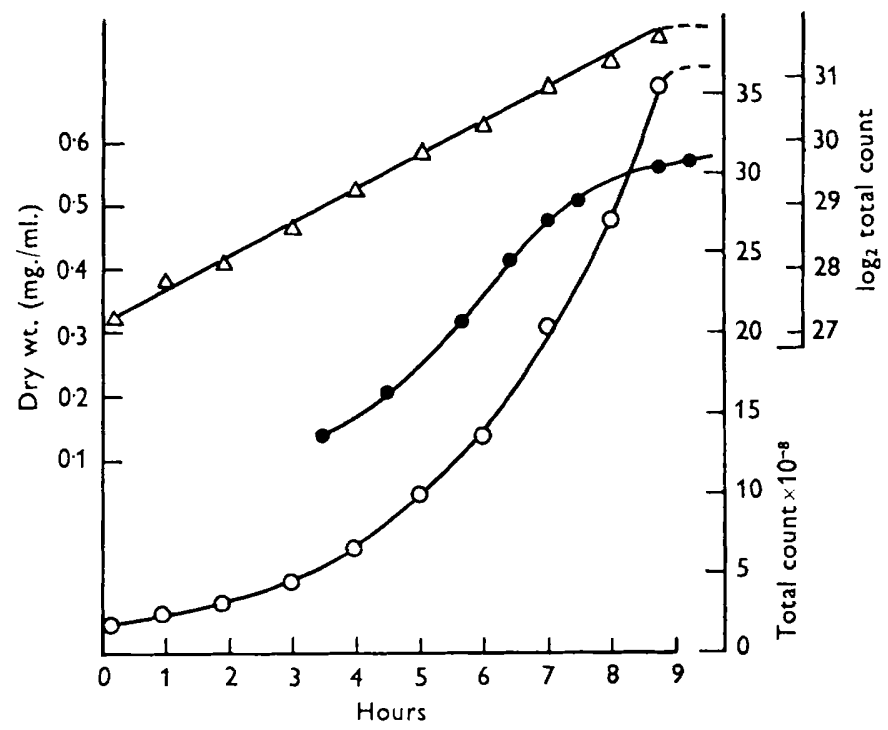

Fig. 1. Curves of growth and of increase in total numbers in a culture containing initially $0.03 \mu$ g. nicotinic acid $/ \mathrm{ml}$. $-\odot$, dry wt.; $\bigcirc-O$, total numbers; $\triangle-\triangle, \log _{2}$ total numbers.

Growth curves, total numbers and cell nitrogen

Curves constructed from estimations of dry weight and of total numbers are shown in Fig. 1. The culture contained initially $0.03 \mu \mathrm{g}$. nicotinic acid $/ \mathrm{ml}$. The total numbers rose exponentially throughout the period of observation. The dry-weight curve was found to show initially an exponential phase after readings became possible, and the terminal portion of this phase is seen in Fig. 1. The exponential phase of synthesis was followed by a phase which was linear for $2 \cdot 5-3 \mathrm{hr}$. and then growth was rapidly retarded. The total numbers did not increase further after the dry weight had become stationary.

During the period of measurement the dry weight increased only by a factor of 4.2 while total count increased seven-fold. This implies a reduction in size of the units counted, and measurements of photographs showed that the reduction is mainly in length of the organisms.

The curve relating cell nitrogen to incubation time showed the same characteristics as the dry-weight curve. 


\section{Disappearance of nicotinic acid from the medium}

A growth experiment was carried out as in the last section with $150 \mathrm{ml}$. medium. Samples $(10 \mathrm{ml}$.) were collected at intervals, cooled and centrifuged at $4^{\circ}$. The supernatant fluids were transferred to $50 \mathrm{ml}$. flasks, re-inoculated and re-incubated. The opacities which developed after $48 \mathrm{hr}$. were measured, and by comparison with a standard curve constructed for the same batches of nicotinic acid and medium at the same time, gave an approximate value for the residual nicotinic acid in the samples. More nicotinic acid was then added to the flasks and incubation was continued. This demonstrated that with adequate nicotinic acid all flasks would show growth to the expected level for the amount added, and that it was due only to lack of nicotinic acid that growth was slight or absent in the samples of supernatant fluid.

The cells from the same samples were washed three times, at $4{ }^{\circ}$ with nicotinic acid-free medium, and were then suspended in nicotinic acid-free medium to a density of about $0.04 \mathrm{mg}$. dry wt. $/ \mathrm{ml}$. Samples of $10 \mathrm{ml}$. were transferred to $50 \mathrm{ml}$. Erlenmeyer flasks and were incubated for $48 \mathrm{hr}$. at which time the opacities were read. Nicotinic acid was then added and incubation was continued to show that those samples in which little or no growth had occurred, would grow if supplied with nicotinic acid.

The results of these experiments (Fig. 2) showed that a considerable increase in dry weight occurred after the disappearance of all detectable nicotinic acid from the medium. The growth curve shows that, following the disappearance of nicotinic acid from the medium, there was, as usual, a phase of more or less linear growth which lasted for $2 \cdot 5-3 \mathrm{hr}$., and that this phase was followed by rapid retardation of growth. During this time, the ability of washed cells to grow on transference to nicotinic acid-free medium progressively decreased.

The effect of adding more nicotinic acid to a culture which was initially provided with a limiting concentration of $0.02 \mu \mathrm{g}$. nicotinic acid $/ \mathrm{ml}$. is shown in Fig. 3. After growth had become measurable the culture was divided into three $50 \mathrm{ml}$. portions, each in a $250 \mathrm{ml}$. llask. Addition of extra nicotinic acid before the end of exponential growth $\left(A_{1}\right)$ did not produce an immediate growth response. By the time the sample to which no extra nicotinic acid was added $\left(\boldsymbol{A}_{3}\right)$ was in the 'linear' phase, $\boldsymbol{A}_{1}$ was still growing exponentially. Addition of more nicotinic acid to the third sample $\left(A_{2}\right)$ during the linear phase of growth was followed by a more rapid response.

\section{Nicotinic acid content of cells}

The amount of nicotinic acid recoverable from the cells in a given volume of culture was found to remain constant during and after the phase of linear growth (Table 1). The quantity of nicotinic acid which could be accounted for by the methods used was only $50-60 \%$ of the nicotinic acid originally present in the medium and the fate of the rest of the nicotinic acid is not known. To find whether nicotinic acid was being destroyed during the extraction process, a known amount of nicotinic acid was added to a cell suspension just before 


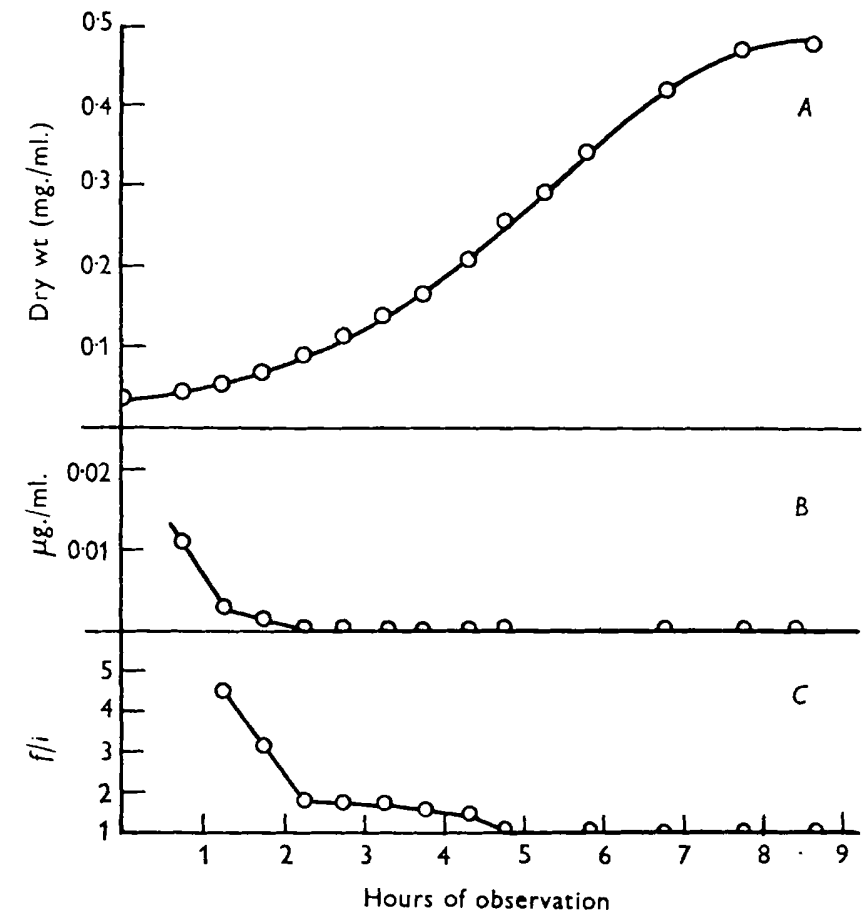

Fig. 2. Nicotinic acid content of medium during growth. The culture contained initially $0.03 \mu$ g. nicotinic acid $/ \mathrm{ml}$. $A$, growth curve; $B$, residual nicotinic acid in supernatant fluid of centrifuged samples; $C$, ability of cells collected at times shown to grow on transference to nicotinic acid-free medium, expressed as ratio of final dry wt./initial dry wt. $(f / i)$.

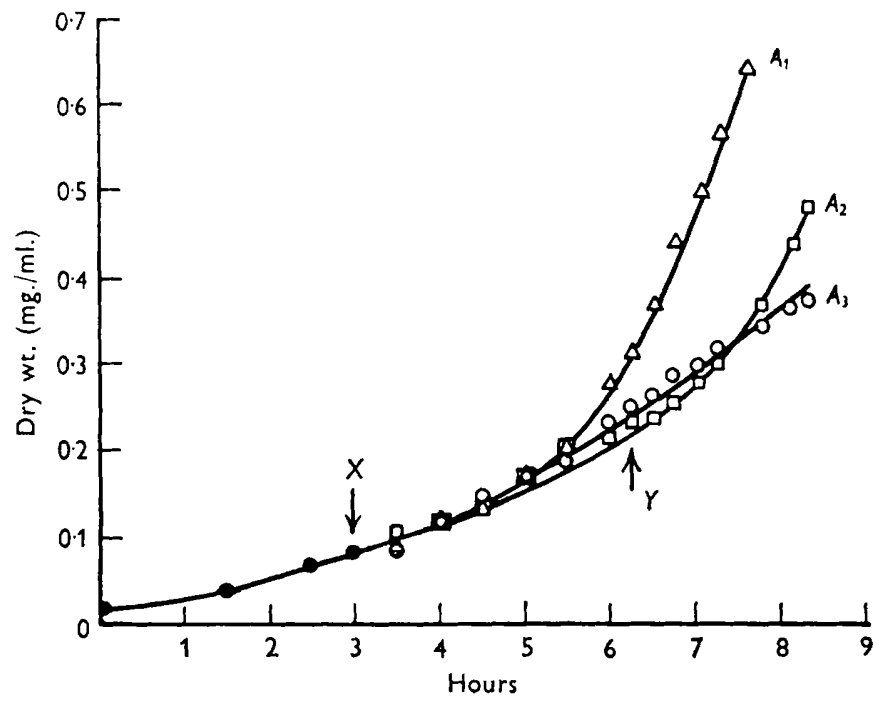

Fig. 3. Effect of adding extra nicotinic acid to a culture which contained initially $0.02 \mu \mathrm{g}$. nicotinic acid $/ \mathrm{ml}$. (O-O). At $X$, the culture was divided into three parts, $A_{1}(\triangle-\triangle)$, $A_{2},(\square-\square)$ and $A_{3},(\bigcirc-\bigcirc), 0.30 \mathrm{ml} .0 .001 \mathrm{M}$ nicotinic acid was added to $A_{1}$; at $Y, 0.30 \mathrm{ml} .0 .001$ m nicotinic acid was added to $A_{2}$. 
autoclaving; on subsequent assay, $95 \%$ was recovered. The figures for nicotinic acid per unit cell mass show that during and after the linear phase of growth there was a progressive dilution of the nicotinic acid in the growing mass of protoplasm.

Table 1. Recovery of nicotinic acid from $\mathrm{P}$. vulgaris cells

\begin{tabular}{|c|c|c|}
\hline $\begin{array}{l}\text { mg. cells/ } \\
200 \mathrm{ml} \text {. } \\
\text { culture }\end{array}$ & $\begin{array}{l}\text { Nicotinic acid } \\
\text { initially present } \\
\text { in medium } \\
\text { recovered from } \\
\text { cells } \\
(\%)\end{array}$ & $\begin{array}{c}\text { m } \mu . \text { moles } \\
\text { nicotinic } \\
\text { acid/mg, dry wt. } \\
\text { cells }\end{array}$ \\
\hline 38 & 57 & 0.73 \\
\hline 41 & 53 & $0 \cdot 63$ \\
\hline 50 & 57 & $0 \cdot 56$ \\
\hline 50 & 53 & 0.52 \\
\hline 102 & 54 & $0 \cdot 26$ \\
\hline 109 & 54 & $0 \cdot 24$ \\
\hline 124 & 55 & $0 \cdot 22$ \\
\hline
\end{tabular}

These estimations were made on a series of similar cultures each containing initially $\mathbf{0} \cdot 03 \mu \mathrm{g}$. nicotinic acid $/ \mathrm{ml}$. medium.

A few estimations were made of the nicotinic acid content of cells which had been grown in the presence of an excess of nicotinic acid $(2 \cdot 4 \mu \mathrm{g} . / \mathrm{ml}$.) and values up to $6 \mathrm{~m} \mu$ moles/mg. dry wt. were found.

\section{Oxygen uptake of growing cultures}

The overall rate of oxygen uptake of a culture growing in a manometer vessel was constant during the period of linear growth (Fig. 4), the $\boldsymbol{Q}_{\mathrm{O}_{2}}$ falling from 330 to 198 during the first $2 \mathrm{hr}$. of this phase. After the period shown in Fig. 4 the rate of oxygen uptake decreased very gradually. A further sample of culture was transferred from the main culture flask to a manometer vessel $24 \mathrm{hr}$. after the end of $B$ and its oxygen uptake was measured for $5 \mathrm{hr}$. (curve $C$, Fig. 4). By the time this sample was taken the dry weight was stationary at $0.55 \mathrm{mg} . / \mathrm{ml}$, and the $Q_{\mathrm{o}_{2}}$ was found to be 56 .

In a further experiment, the effect on oxygen uptake of adding extra nicotinic acid $\left(0.20 \mathrm{ml}\right.$. of $\left.2.5 \times 10^{-5} \mathrm{M}\right)$ to a $2.6 \mathrm{ml}$. sample of culture growing in the linear phase was observed. There was a prompt increase in rate of oxygen uptake, the $Q_{\mathrm{O}_{2}}$ rising from 208 to 300 in $10 \mathrm{~min}$.

\section{DISCUSSION}

It is possible to interpret the curves of growth and of rates of oxygen uptake as showing that, after assimilation of all the nicotinic acid from the medium, the amount of active nicotinic acid derivatives formed within the cells is sufficient to maintain the rate of protoplasmic synthesis constant for a definite period. Our results have shown that at the time when nicotinic acid disappears from the medium exponential growth ceases and is followed by a linear growth phase during which the rate of oxygen uptake is constant. The constant rate 
of oxygen uptake under conditions where only nicotinic acid is limiting for growth is consistent with the hypothesis that there is a constant amount of some catalytic factor controlling the rate of oxygen uptake within the culture. Therefore, in so far as the organism has no other means of deriving energy from the environment, a linear growth phase would be expected. An analogous

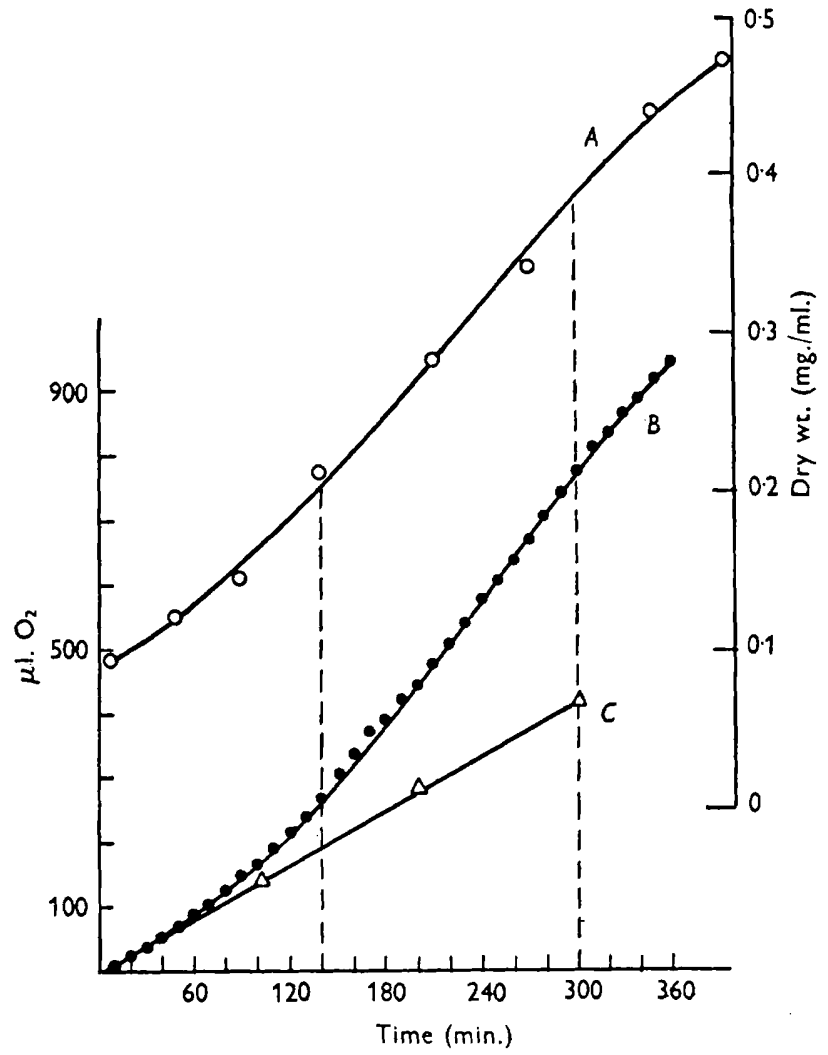

Fig. 4. Rate of oxygen uptake of a culture containing initially $0.03 \mu \mathrm{g}$. nicotinic acid $/ \mathrm{ml}$. $A$, growth curve $(\mathrm{O}-\mathrm{O}) ; B$, rate of $\mathrm{O}_{2}$ uptake of a sample corresponding to $A(-)$; , rate of $\mathrm{O}_{2}$ uptake of a sample of the same culture collected $24 \mathrm{hr}$. later $(\triangle-\triangle)$.

example of linear growth, in a streptomycin-requiring strain of Bacillus cereus deprived of streptomycin was reported by Schaeffer (1950), and Monod (1949) has discussed the significance of linear growth. It is, however, possible that in a culture whose growth is being limited by lack of nicotinic acid, the derivatives are being broken down, but are also being resynthesized from their breakdown products, so that for a time corresponding to the linear growth phase the rates of breakdown and resynthesis are balanced. Mcllwain \& Hughes (1948) showed that some bacteria actively decompose cozymase and that different organisms vary in their ability to resynthesize it. Nicotinamide and nicotinic acid may both occur as breakdown products of cozymase and from these Proteus can effect the resynthesis. 
Linear growth lasts in our cultures for $2 \cdot 5-3 \mathrm{hr}$, and it is clear that its cessation might be due to the interplay of several factors, such as gradual irreversible inactivation of some of the coenzymes (see Morel, 1941), and dilution, to below a critical threshold concentration, of the nicotinic acid derivatives in the growing mass of protoplasm. It is possible that for protoplasmic synthesis to occur, certain structural relationships between coenzymerequiring systems within the cell are necessary. Progressive separation, during growth, of active centres containing coenzyme might, therefore, lead to decrease in rate of protoplasmic synthesis even if the total amount of active coenzyme within the culture remained constant. Moreover, some apoenzymes may have a greater affinity than others for a particular coenzyme, so that with limitation of coenzyme supply the balance of distribution among the apoenzymes might be altered.

Failure to recover from the cells all the nicotinic acid originally added to the culture might possibly result from firm binding of some nicotinic acid to cell constituents so that it was not released by the methods used; in addition, part of the nicotinic acid might have been completely inactivated during growth. There is, however, some evidence that derivatives other than the pyridine nucleotides may play a part in the metabolism of Proteus (McIlwain, 1940; Saunders, Dorfman \& Koser, 1941). The apparent loss of nicotinic acid in the present experiments might be at least partly explained on this basis if the unknown derivatives were not estimated by the methods used.

The continued exponential increase in numbers of bacteria during the linear growth phase of bacterial protoplasm shows that, in the present instance, the rate of cell division is less immediately affected by shortage of nicotinic acid than is the rate of protoplasmic synthesis. This dissociation between the two rates inevitably leads to progressive decrease in cell size, a phenomenon well known to occur during the later growth phases (Henrici, 1928).

We are indebted to Dr M. R. Pollock for suggesting the problem to us and for much advice during the course of the work. We also wish to thank Miss L. Hopkinson for her technical assistance and Miss K. de Bouk for advice on the assay of nicotinic acid.

\section{REFERENCES}

Barton-Wright, E. C. (1946). Practical Methods for the Microbiological Assay of the Vitamin B Complex and Essential Amino-acids. London: Ashe Laboratories, Ltd.

Fildes, P. (1938). The growth of Proteus on ammonium lactate plus nicotinic acid. Brit. J. exp. Path. 19, 239.

Henrici, A. T. (1928). Morphologic Variation and the Rate of Growth of Bacteria. Springfield, Ill.: Charles C. Thomas.

McIlwain, H. (1940). Pyridine-3-sulphonic acid and its amide as inhibitors of bacterial growth. Brit. J. exp. Path. 21, 136.

McIlwaix, H. \& Hughes, D. E. (1948). Decomposition and synthesis of cozymase by bacteria. Biochem. J. 43, 60 .

Miles, A. A. \& Misra, S. S. (1938). The estimation of the bactericidal power of the blood. J. Hyg., Camb. 38, 732.

Miller, L. \& Houghton, J. A. (1945). The micro-kjeldahl determination of the nitrogen content of amino-acids and proteins. J. biol. Chem. 159, 373. 
Monod, J. (1949). The growth of bacterial cultures. Ann. Rev. Microbiol. 3, 371.

Mores, M. (1941). L'usure de la nicotinamide chez Proteus vulgaris. Ann. Inst. Pasteur, 67, 285.

Saunders, F., Dorfman, A. \& Koser, S. A. (1941). The role of nicotinamide and related compounds in the metabolism of certain bacteria. J. biol. Chem. 138, 69.

Schaeffer, P. (1950). Croissance et respiration d'une souche streptomycinoexigeante de Bacillus cereus privée de l'antibiotique-facteur de croissance. Ann. Inst. Pasteur, 78, 624.

Sykes, J. A. \& ReEd, R. (1949). The control of the swarming of Proteus vulgaris by boric acid. J. gen. Microbiol. 3, 117.

WiLson, G. S. (1922). The proportion of viable bacteria in young cultures with especial reference to the technique employed in counting. J. Bact. 7, 405.

Wrigut, H. D. (1933). The importance of adequate reduction of peptone in the preparation of media for the pneumococcus and other organisms. J. Path. Bact. $37,257$.

(Received 9 February 1952) 